\title{
REORGANIZAÇÃO ESPACIAL DE REDES BANCÁRIAS NO BRASIL: processos adaptativos e inovadores ${ }^{1}$
}

\author{
Leila Christina Dias* \\ Maria Helena Len₹i**
}

\begin{abstract}
O trabalho analisa a reorganização espacial de três redes bancárias privadas - Bradesco, Bamerindus (atual HSBC) e Unibanco - que surgem na primeira metade do século XX em São Paulo, Paraná e Minas Gerais. Como evoluíram essas redes bancárias? Como interagiram com outros processos que moldam sua extensão territorial e social? $\mathrm{O}$ artigo examina os condicionantes externos e internos que mudaram a trajetória do sistema bancário no Brasil e apresenta um conjunto de mapas que mostram a localização das redes de agências desses bancos e suas mudanças locacionais (1986-1996 e 1996-2005). O texto conclui que a reorganização resultou da combinação de processos adaptativos e inovativos que demandaram uma nova geografia ajustada às condições macro e microeconômicas emergentes. Nesse processo os bancos inventaram ou reinventaram o correspondente bancário, objeto híbrido que combina serviço, tecnologia de comunicação e produto, viabilizando uma expansão territorial e social sem precedentes no território brasileiro.

PALAVRAS-CHAVE: rede bancária, reorganização espacial, sistema bancário, cartografia das redes,
\end{abstract} território

\section{INTRODUÇÃO}

Um dos traços mais marcantes da economia mundial neste início de século é a magnitude e a velocidade crescentes dos fluxos de capitais que atravessam as fronteiras nacionais. François Chesnais (1998) utiliza o conceito de mundialização financeira para designar a emergência de um espaço financeiro mundial resultante da liberalização e da desregulamentação iniciada pelos Estados Unidos nos anos setenta do século XX. As bases técnicas da desregulamentação encontram-se nos avanços extraordinários na capacidade de tratar informações e transmiti-las de um lugar a outro do planeta. Contudo esses processos não devem ocultar

* Doutora em Geografia pela Universidade de Paris IV. Professora do Departamento de Geociências da Universidade Federal de Santa Catarina.

Departamento de Geociências, Centro de Filosofia e Ciências Humanas. Campus Universitário, Trindade. Cep: 88040970 - Florianópolis - Santa Catarina. leila@cfh.ufsc.br

* * Mestranda em Geografia - Programa de Pós Graduação em Geografia/UFSC. prenom.marie@gmail.com

${ }^{1}$ Este trabalho se inscreve no âmbito de um projeto de pesquisa em curso, com apoio do CNPq, intitulado "Redes financeiras e dinâmica territorial brasileira: a construção de novas escalas geográficas”. as complexas interações do sistema mundial com os espaços nacionais (Martin, 1999; Plihon, 2000;

Santos; Silveira, 2001; Dias, 2006). Longe de "negar o espaço", 2 a integração virtual dos lugares em escala mundial e a mundialização financeira vêm reafirmando o valor estratégico da localização geográfica. Isso significa que ações extranacionais não incidem sobre "espaços vazios", mas sobre espaços geográficos que elas vão certamente influenciar, mas de onde também vão receber a marca. Em outras palavras, a mundialização ou globalização financeira não constituiria um processo exógeno, que impactaria os países de cima para baixo, mas seria antes um processo geográfico,

... produto das estratégias organizacionais, tecnológicas, regulatórias e corporativas de firmas individuais, instituições e autoridades em localizações específicas (Martin, 1999, p. 15).

${ }^{2}$ Ideia defendida por Paul Virilio, na obra Vitesse et Politique (1977). Segundo o autor, "a contração das distâncias se tornou uma realidade estratégica de consequências econômicas incalculáveis, pois corresponde à negação do espaço [..] a localização geográfica parece ter definitivamente perdido seu valor estratégico" (p. 131, 133). 
Instáveis no tempo, móveis e inacabadas, as redes dos maiores bancos privados chamam a atenção para formas particulares de reorganização da atividade financeira, resultantes de ações empreendidas em diferentes escalas espaciais. Nossa hipótese é que as mudanças econômica, tecnológica, normativa, política e espacial estão articuladas num só conjunto interdependente, resultante do encontro entre a internacionalização das finanças e os determinantes internos a cada Estado-Nação (históricos, geográficos, econômicos, organizacionais e políticos). Partimos de uma compreensão do espaço geográfico como sistema relacional em permanente movimento: ações sociais dependem de certa disposição física dos objetos, o que, por sua vez, permite a produção de determinadas ações, numa relação dialética e inconclusa (Santos, 1996).

Neste trabalho, analisamos a reorganização espacial de três redes bancárias privadas, de origem e desenvolvimento inicial semelhante. Bradesco, Bamerindus (atual HSBC) e Unibanco surgem na primeira metade do século XX em pontos dos estados de São Paulo, Paraná e Minas Gerais, evoluem para redes regionais nos anos sessenta e configuram redes nacionais nos anos setenta. Desde então, como evoluíram essas redes bancárias? Como interagiram com outros processos que moldam sua extensão territorial e social? Através de uma periodização, procuramos compreender mudanças na localização das agências bancárias, identificando os nexos que, a cada período, transformam a geografia das redes bancárias. Nossa hipótese é que a relocalização espacial das agências, nas últimas duas décadas, revela um movimento que transcende a diferenciação regional ou estadual, apontando novas diferenças, como a que resulta da forte retração de agências bancárias no interior de todas as macrorregiões brasileiras e da expansão de agências bancárias em direção às regióes metropolitanas e aos pontos economicamente mais dinâmicos do Centro-Sul brasileiro (Dias, 1999, 2006; Scherer-Warren, 1999; Videira, 1999, 2006; Khalil, 2004; Lenzi, 2006). Na tentativa de representar essa dinâmica, elaboramos um conjunto de mapas que apresentam a localização das redes de agências desses três bancos, por municípios, em três momentos do tempo - 1986, 1996 e 2005 - e as mudanças locacionais ocorridas entre 1986 e 1996, e entre 1996 e 2005.

\section{DE PONTOS A REDES NACIONAIS}

Na zona de produção cafeeira do norte velho paranaense, Avelino Vieira funda em 1929, na cidade de Tomazina, a Sociedade Cooperativa de Responsabilidade Limitada Banco Popular e Agrícola do Norte do Paraná, quinze anos mais tarde incorporada pelo então maior banco privado paranaense-Banco Comercial do Paraná; em 1952, funda o Banco Mercantil e Industrial do Paraná S.A., que tem sua razão social alterada para Banco Bamerindus do Brasil S. A. em 1971 (Tavares, 1996). Em 1940, a seção bancária da Casa Moreira Salles, localizada em Poços de Caldas, Estado de Minas Gerais, obtém a carta-patente para funcionar como banco, que viria a denominar-se Unibanco em 1967, após fundir-se com o Banco Agrícola Mercantil (Agrimer). Em 1943, o Banco Brasileiro de Descontos S.A. - Bradesco - é fundado em Marília, cidade do interior do Estado de São Paulo. A uni-los, há a origem comum: pequenos estabelecimentos bancários locais no centro de vastas zonas de produção agrícola.

Quinhentos e doze bancos operavam no país em 1941 (Corrêa, 1989). Num contexto de proliferação de numerosos pequenos estabelecimentos bancários locais, a necessidade de reorganizar os sistemas financeiro e bancário era apontada desde fins da década de quarenta, em sucessivos documentos publicados pela Superintendência da Moeda e do Crédito (SUMOC), instituição criada em 1945 para exercer o controle monetário, preparar a organização de um futuro Banco Central, supervisionar a atuação dos bancos comerciais, orientar a política cambial e representar o país junto a organismos internacionais (Banco Central, 2008). Em consonância com a tendência mundial de redução do número de bancos, a SUMOC revela sua posi- 
ção favorável à concentração bancária no Brasil e antecipa a necessidade de fusão e incorporação de estabelecimentos bancários, eventos que, de fato, só aconteceriam após a reforma financeira de 1964. Em face do reconhecimento da tendência de forte concentração geográfica das agências em certos pontos do território nacional, a SUMOC estabelece critérios para orientar a instalação de agências bancárias no país, chamando a atenção para a necessidade de compatibilizar número de agências e necessidade real dos lugares.

As circulares e instruções expedidas pela SUMOC na década de 50 se inserem num prolongado debate que teve início com a decisão do Governo Dutra de elaborar, desde 1946, um projeto de reforma bancária, finalmente encaminhado ao Congresso no ano seguinte (Tavares, 1996, p. 28).

A partir de então, a lenta tramitação parlamentar da reforma expressa os conflitos entre forças sociais e políticas, representadas pelos partidos e pelas associações e sindicatos de classe (banqueiros, industriais, bancários e trabalhadores).

O ritmo acelerado do processo de industrialização no governo de Juscelino Kubitschek (19561961) ajustou-se a um sistema financeiro no qual ainda prevalecem formas de crédito e de financiamento herdadas do início do século, além de esbarrar num sistema de telecomunicações obsoleto e lacunar. Tal situação não seria tolerada por muito tempo: articulados a um vasto projeto de formação científica e tecnológica, de modernização da economia e de reorganização espacial, uma política de telecomunicações e uma reforma financeira seguiram de perto o golpe militar de 1964, que consagra as principais reivindicações dos banqueiros através da Lei $\mathrm{n}^{\circ} 4595$, de 31/12/64, que passa a estruturar e regular o nascente sistema financeiro nacional (SFN). Dentre outras regulamentações, a lei transforma a SUMOC em Banco Central e cria o Conselho Monetário Nacional. Como afirma Minella:

Na verdade, o sistema bancário teria agora a importante função de, juntamente com o capital financeiro internacional, sustentar o projeto político-econômico delineado pela nova composição de forças no poder (1988, p. 71).
O objeto da Lei 4595 é mais do que uma simples reforma bancária: marca o início de um longo processo de integração financeira do território brasileiro, que nos anos seguintes transformaria a geografia dos bancos, pela constituição de grandes redes bancárias em escala nacional. Em menos de dez anos, mais de trezentas resoluções do Banco Central organizam o SFN. Normas são impostas a fim de restringir a concentração de agências nas maiores cidades do país e favorecer a expansão das redes de agências em direção às áreas até então desassistidas.

Nos anos setenta, já se esboçam as primeiras redes bancárias nacionais, como ilustra a trajetória do Bradesco (Banco Brasileiro de Descontos S.A). Multiplicando os investimentos, e priorizando as zonas agrícolas, o Bradesco conquista, nos anos quarenta, o estado de São Paulo e o Norte do Paraná. Nos anos seguintes, o banco se instala nos estados vizinhos: Rio de Janeiro, Minas Gerais, Mato Grosso e Goiás. A rede de agências, em 1960, traduz uma etapa no processo de unificação do mercado nacional: a integração das zonas agrícolas e industriais localizadas no estado de São Paulo e nos estados vizinhos é comandada pela aglomeração paulista. Entre 1965 e 1973, o Bradesco realiza 14 incorporações (Gomes, 2000), o que lhe permitiu estar presente em quase todos os estados da federação, constituindo uma rede nacional que não cessa de crescer nos anos seguintes, quando o banco projeta sua ação por todo o território, até os seus limites mais extremos (Mapa 1).

A ampliação da rede do Banco Bamerindus seguiu a lógica da divisão regional do banco, organizado originalmente em sete matrizes: Banco Mercantil e Industrial do Paraná, de São Paulo, do Rio de Janeiro, do Rio Grande do Sul, de Santa Catarina, de Mato Grosso e do Nordeste. Em razão da reforma financeira pós-golpe militar de 1964, as sete matrizes regionais foram unificadas, e mais quatro bancos seriam adquiridos pelo Bamerindus. Progressivamente, a rede se expande pelo território nacional. A partir dos anos setenta, a presença do Bamerindus na Região Centro-Oeste acompanha o processo de modernização agroindustrial em 
curso, inicialmente no Estado do Mato Grosso do Sul, em seguida nos Estados de Mato Grosso e Rondônia (Mapa 2).

No início dos anos quarenta, a casa bancária Moreira Salles abre agências na capital federal - cidade do Rio de Janeiro - e na capital paulista. Progressivamente, a rede bancária regional que operava no sul de Minas Gerais se transforma em rede nacional. Em 1966, a instituição funda o Banco de Investimento do Brasil (BIB), que um ano depois se fundiria com o Agrimer (Banco Agrícola Mercantil), passando a denominar-se União de Bancos Brasileiros S.A., mais conhecida como Unibanco. Em 1970, já com sua sede no Rio de Janeiro, incorpora o Banco Predial do Estado do Rio de Janeiro, expandindo-se nessa cidade mais do que em outras (Costa, 2002). A configuração de sua rede bancária, em 1986, revela estratégia locacional bem mais seletiva do que a dos outros dois bancos aqui analisados, estando majoritariamente presente nos lugares mais urbanizados e desenvolvidos do país (Mapa 3).
No Brasil, bancos foram pioneiros no uso de computadores e obtiveram êxito no desenvolvimento de inovações tecnológicas que encurtam o tempo de realização de operações, como compensação de cheques, títulos de cobrança, investimentos e transferência de recursos (Pereira, 1995; Antunes, 2000). Por pressão do sistema financeiro, foram instalados circuitos nacionais e internacionais de comunicação de dados: a Embratel cria a rede Transdata em 1981, e, um ano mais tarde, a Society for Worldwide Interbank Financial Telecommunications (SWIFT) estende sua rede de transmissão de dados ao Brasil (Dias, 1995). A implantação de novas tecnologias informacionais e organizacionais possibilitou a ampla difusão de agências do Bradesco, do Bamerindus e do Unibanco pelo território nacional (Dias, 1995; Tavares, 1996; Gomes, 2000; Costa, 2000).

A formação de redes mais abrangentes foi acompanhada por espetacular redução do número de praças bancárias e pela emergência da cidade de São Paulo como principal centro de controle da

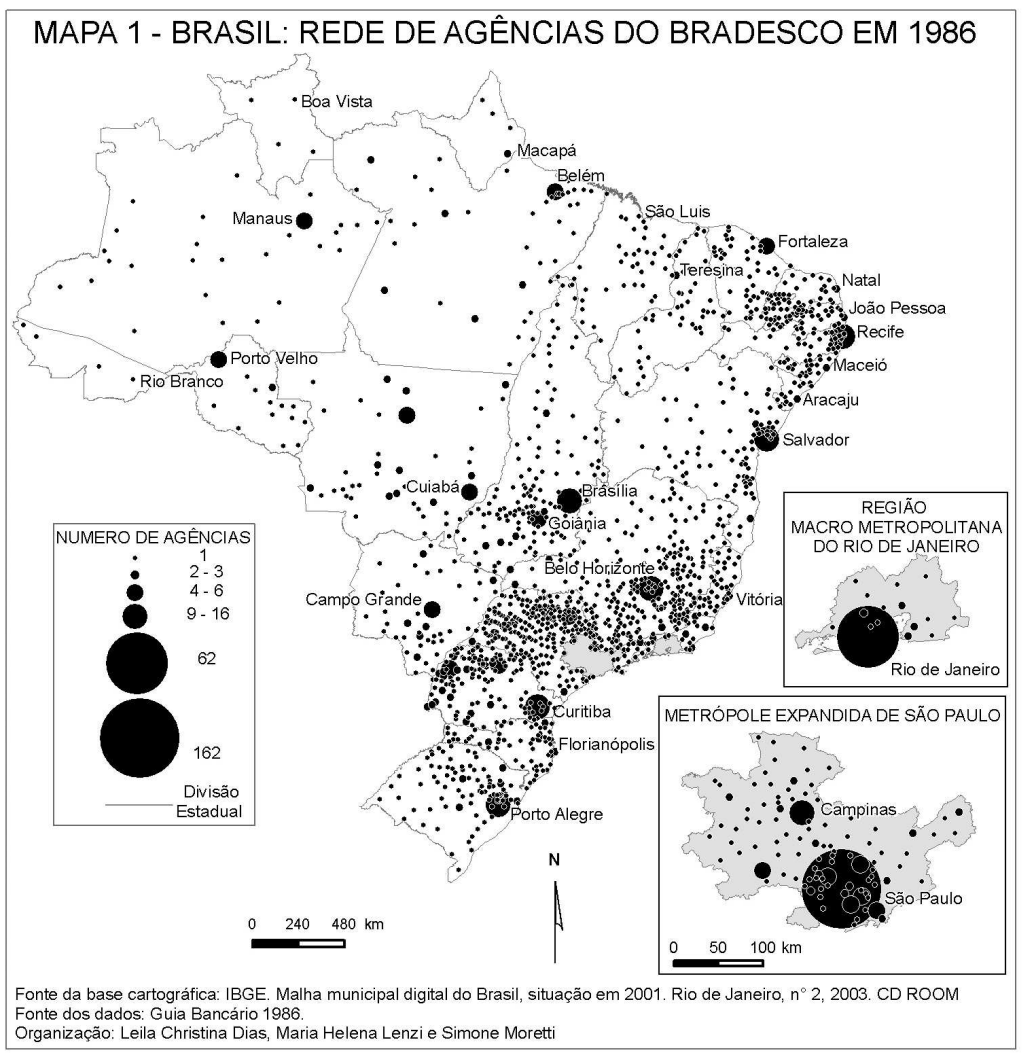



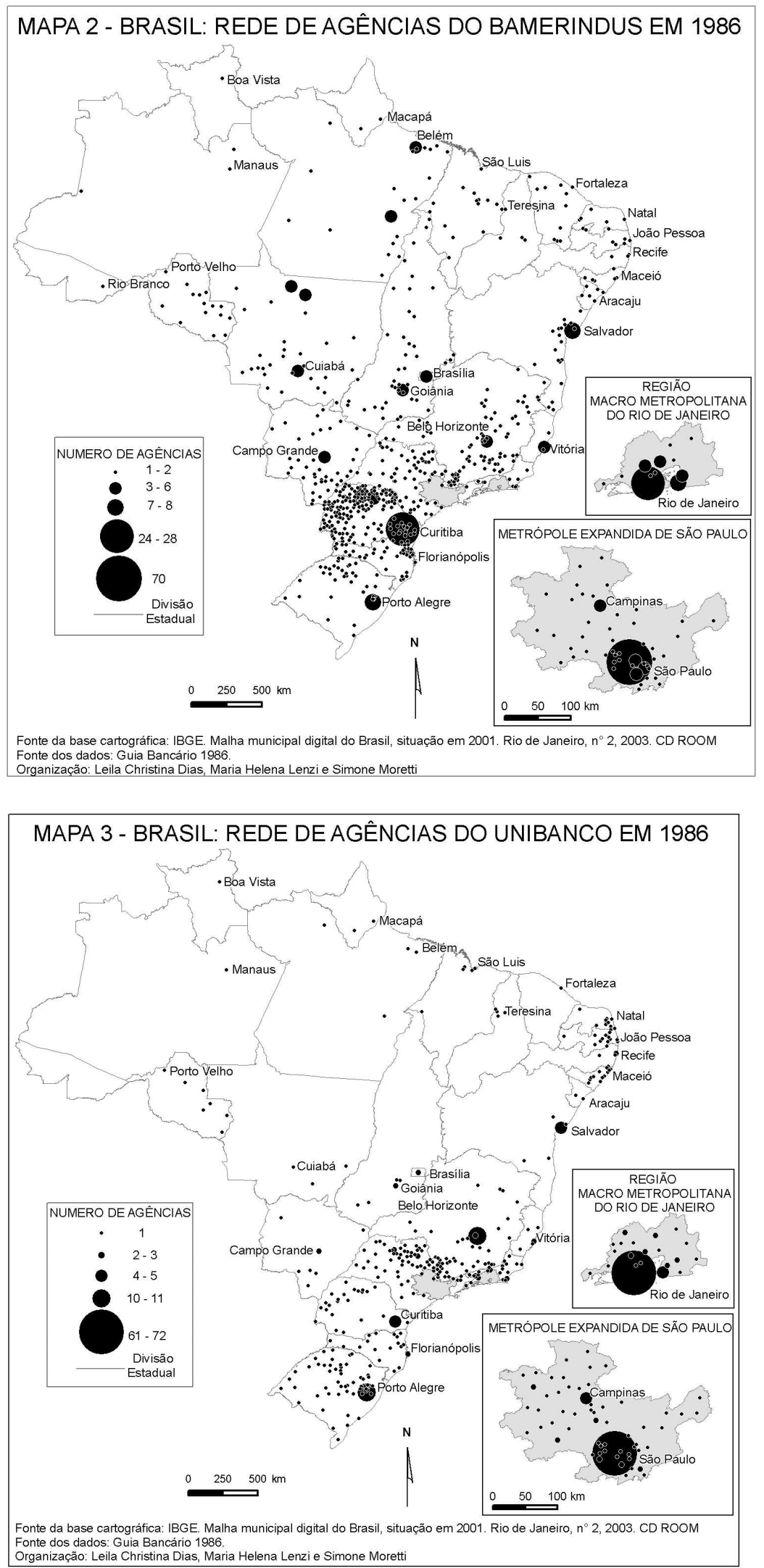
atividade bancária no país: entre 1961 e 1986, o número de centros urbanos que acolhe sedes de bancos decresce de 77 para 28; no mesmo período, a participação relativa da metrópole paulista no conjunto das cidades controladoras da atividade bancária passa de $22 \%$ para $36 \%$, superando a da cidade do Rio de Janeiro, que, em 1961, ocupava a primeira posição, quando acolhia 30\% das sedes dos bancos comerciais que operavam no país.

\section{MUDANÇAS NA TRAJETÓRIA DO SISTEMA BANCÁRIO}

Na mesma medida em que os diversos países criam novos sistemas de normas para regulamentar o mercado financeiro e bancário e a concorrência entre as instituições alcança escala planetária, os sistemas financeiro e bancário no Brasil tomam nova direção. É nesse contexto que se inscreve o processo de desregulamentação, iniciado em 1988, quando o BC, por meio das Resoluções $\mathrm{n}^{\mathrm{0}} 1.524$ daquele ano, facultou aos bancos comerciais, aos bancos de investimento, aos bancos de desenvolvimento, às sociedades de crédito imobiliário e às sociedades de crédito, financiamento e investimentos a organização de uma única instituição financeira com personalidade jurídica própria, autorizando a criação dos bancos múltiplos ou universais. Ao mesmo tempo, o sistema de cartas patentes e de pontuação é extinto, autorizando empresas comerciais e industriais a ingressarem e concorrerem no sistema bancário. Num primeiro momento, essa reorganização institucional engendra significativo crescimento no número de bancos que operam no país. De pequeno e de médio porte, novos bancos são constituídos como resultado da transformação de corretoras e financeiras em bancos múltiplos (Cerqueira; Amorim, 1997). Em consequencia, o número de bancos mais do que duplica entre 1988 e 1990. Essa trajetória de crescimento só seria interrompida após a implantação do Plano Real em 1994. Desde então, o número de bancos no país não cessa de decrescer. Qual o sentido dessa inversão de tendência? Em que medida a reorganização mais ampla do sistema bancário no país, iniciada na segunda metade dos anos oitenta do século XX, implica nova disposição espacial das agências bancárias?

\section{Processos adaptativos e geografia das redes bancárias pós-1994}

O sistema financeiro e particularmente o bancário beneficiaram-se do cenário inflacionário, presente na economia brasileira desde a década de sessenta. Os bancos lucravam com as receitas obtidas pelofloating - recursos em trânsito - e com o financiamento do desequilíbrio das contas públicas. Os planos econômicos de combate à inflação - Plano Cruzado (1986), Plano Verão (1989) e Planos Collor (1990-1991) - mostraram as dificuldades de o sistema bancário vigente manter-se numa conjuntura de estabilidade da moeda. A baixa capacidade competitiva dos bancos ficou evidente com o fim do uso das receitas inflacionárias que majoravam lucros efinanciavam investimentos. O crescimento dos empréstimos de liquidação duvidosa também denota a vulnerabilidade de algumas instituições, como o Banco Nacional, que procuram, através de receitas fictícias, melhorar seus demonstrativos financeiros e manter boa imagem de credibilidade (Silva, 1997). A implantação do Programa Brasileiro de Estabilização Econômica (Plano Real) em 1994 inaugura uma longa série de planos econômicos que dão continuidade ao processo de reorganização iniciado em 1988. Interlocutor de primeira grandeza com os atores internacionais, o Banco Central do Brasil (BC) cria progressivamente um conjunto de normas, através de resoluções e de programas específicos, que adaptam o sistema financeiro à “opinião” internacional e redesenham o quadro institucional no qual operam os bancos. Em primeiro lugar, recomenda a adaptação das instituições financeiras aos princípios do Acordo da Basileia, dispondo sobre a obrigatoriedade de manter patrimônio líquido em valor compatível com o grau de risco das operações ativas das instituições financeiras. Em segundo lugar, após uma sucessão de intervenções e liquidações que envolve- 
ram vinte e dois bancos em menos de dezoito meses, o BC implanta, em 1995, o Programa de Estímulo à Reestruturação e ao Fortalecimento do Sistema Financeiro Nacional (PROER), que disciplina

as aquisições de bancos com problemas patrimoniais e de solvência por meio da criação de linhas de crédito, de incentivos fiscais, de benefícios tributários e de isenção temporária do cumprimento de determinadas regulamentações bancárias" (Corazza; Oliveira, 2006, p. 6). ${ }^{3}$

Mudanças nas estruturas patrimoniais e operacionais, incluindo fusões e incorporações, e no padrão de rentabilidade (Paula; Marques, 2004) configuram processos adaptativos à desregulamentação do sistema financeiro à escala internacional. Nossa hipótese é que mudanças espaciais nas redes de agências bancárias constituem também um processo adaptativo às novas condições econômicas e políticas vigentes. Os bancos planejam e realizam movimentos, inclusive espaciais, visando a alcançar um objetivo, mantendo posições relativas favoráveis a futuras ações.

Em 1996, identifica-se uma primeira fase na reorganização espacial das redes, em relação à reorganização mais ampla do sistema bancário no Brasil. O estudo de Scherer-Warren (1999) sobre mudanças no padrão de localização das redes dos cinco maiores bancos privados nacionais Bradesco, Itaú, Bamerindus, Real e Unibanco concluiu que a concentração geográfica bancária cresceu entre 1986 e 1996: enquanto o número de municípios integrados pelas redes dos cinco maiores bancos decresceu 30,83\% (de 2212 para 1530 ), o número de agências caiu apenas 1,74\% (de 5495 para 5399). Mas esses dados não devem ocultar diferenças significativas entre os bancos nos processos de reorganização espacial de suas redes, como indicam as trajetórias do Bradesco, do Bamerindus e do Unibanco.

O Bradesco ocupou, durante longo período da história econômica recente do país, a posição

3 “Os recursos investidos no Proer somaram R\$ 21 bilhões, o equivalente a $2,5 \%$ do PIB. Embora elevado, este custo foi menor, se comparado com o de outros países da América Latina, onde ocorreram processos semelhantes" (Corazza; Oliveira, 2000, p. 7). de maior banco privado nacional. ${ }^{4}$ Nos anos setenta e oitenta, sua rede expandiu-se por todo o território nacional, em consonância com as ações normativas do BC de ampliar a assistência bancária a municípios desassistidos (Dias, 1999; Almeida; Jaime Jr., 2007). Altos ganhos inflacionários davam-lhe a condição de estar presente em municípios mais pobres, onde, muitas vezes, era o único banco a operar. O fim do ciclo inflacionário e a necessária adaptação ao contexto de relativa estabilidade econômica levaram-no a reduzir sua rede de agências. Entre 1986 e 1996, os municípios integrados pela rede reduziram-se de 1616 para 1254, e as agências, de 2082 para 1852. A configuração espacial de sua rede de agências em 1996 é distinta e muito mais seletiva do que a que dominou até meados dos anos oitenta. A representação cartográfica das mudanças locacionais do Bradesco, entre 1986 e 1996, revela a coexistência de duas dinâmicas: forte retração em todas as macrorregiões brasileiras, particularmente no Norte e no Nordeste, onde vastos territórios são completamente varridos do mapa bancário (o número de municípios integrados pela rede decresce $55 \%$ no Nordeste), e expansão na direção das maiores regiões metropolitanas do país, das capitais estaduais e das cidades economicamente mais dinâmicas, localizadas nos estados de São Paulo e do Paraná e no litoral catarinense (Mapas 4 e 5).

Diferentemente do Bradesco e de outros grandes bancos do país naquela época - como o Itaú e o Real (Scherer-Warren, 1999) -, o Bamerindus amplia sua presença no território nacional entre 1986 e 1996, integrando um número maior de municípios (de 702 para 961), e de agências (de 935 para 1380). Da sua histórica sede em Curitiba, o banco expande-se na Região Sul, no Sudeste, em alguns pontos do Nordeste e no Centro-Oeste, especialmente nos Estados do Mato Grosso do Sul e do Tocantins, onde convênios com os governos estaduais asseguram-lhe o direito de atuar como verdadeiro banco oficial, funcionando como caixa

${ }^{4}$ Em meados de 2008, a fusão entre Unibanco e Itaú deixa o Bradesco em segundo lugar no ranking dos maiores bancos privados do país, após décadas de liderança. 

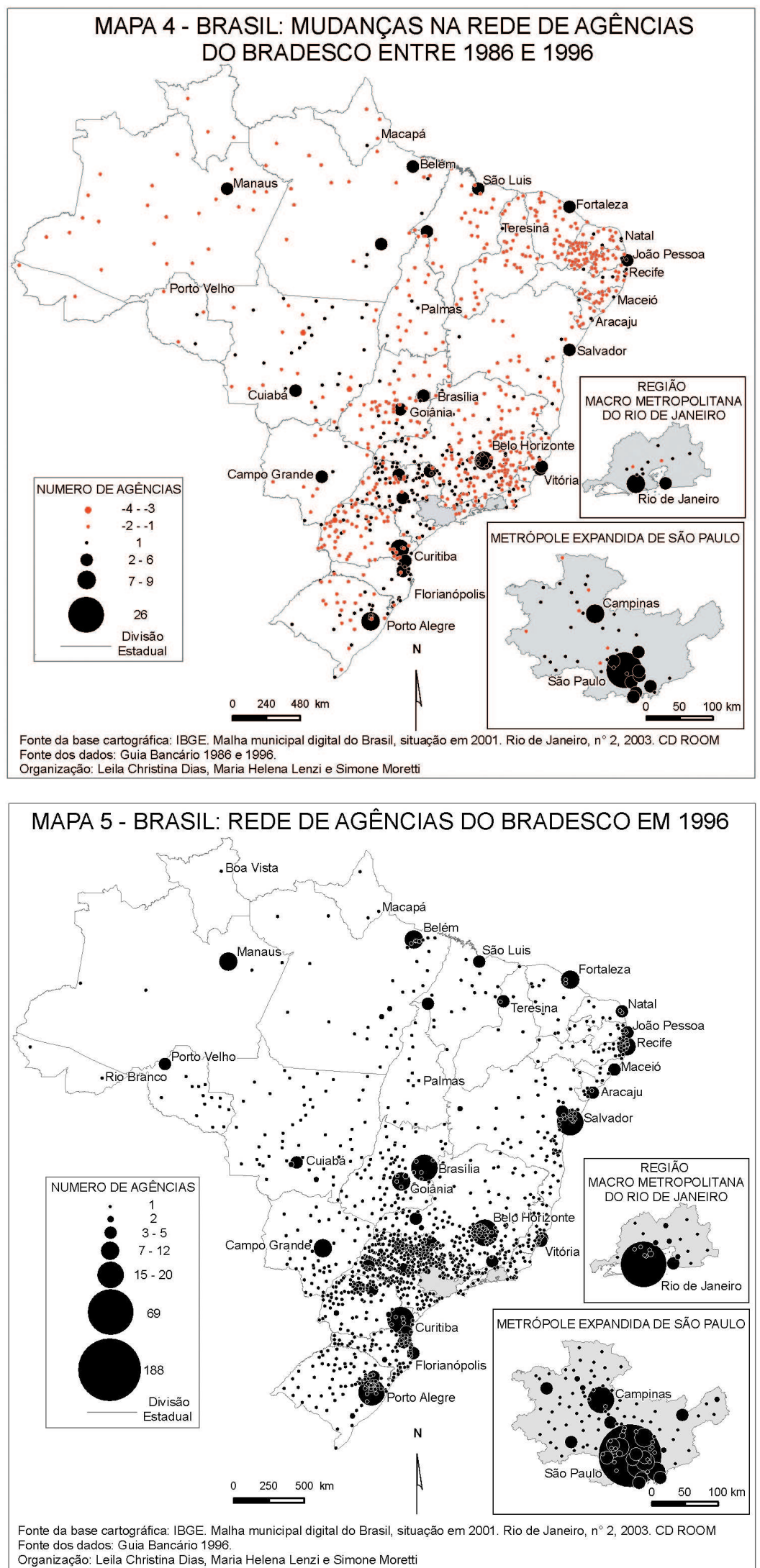
único do Tesouro Estadual (Tavares, 1996) (Mapas 6 e 7).

Apontando para uma terceira estratégia locacional, o Unibanco amplia sua rede de agências (de 596 para 783) e reduz o número de municípios atendidos, de 402 para 273, concentrando geograficamente ainda mais suas agências. $\mathrm{O}$ banco expande-se tão somente nos limites da chamada região concentrada ${ }^{5} \mathrm{e}$ nas maiores regiões metropolitanas, especialmente nas duas principais metrópoles brasileiras, e retira-se completamente do interior das Regiões Nordeste e Norte, e até mesmo de algumas de suas capitais, como Boa Vista e Macapá. Diferentemente do Bradesco e do Bamerindus, a expansão do Unibanco entre 1986 e 1996 é maior na metrópole carioca do que na metrópole paulista - herança da localização de sua sede, até 1983, na antiga capital federal-, e distribui suas agências de maneira equitativa entre essas duas metrópoles (Mapas 8 e 9).
O rearranjo espacial dos bancos Bradesco, Bamerindus e Unibanco entre 1986 e 1996 revela distintas estratégias locacionais. Chama particularmente atenção a expansão territorial do Bamerindus, num contexto de crise bancária provocada pelo Plano Real e pela vulnerabilidade microeconômica de muitos bancos. Nos cinco anos anteriores à implantação do Plano Real, o Bamerindus apresenta rentabilidade inferior à média dos sete maiores bancos que operam no país, além de ativos considerados de má qualidade (Corazza, 2000), mas não adapta geograficamente sua rede de agências à nova conjuntura política e econômica. As redes dos três bancos analisados não se expandiram na mesma direção - excetuando-se as regiões metropolitanas -, porque a decisão sobre a localização de agências depende da memória do passado e da antecipação do futuro. Como essa disposição espacial das agências implicará novas ações? Como a combinação de estra-

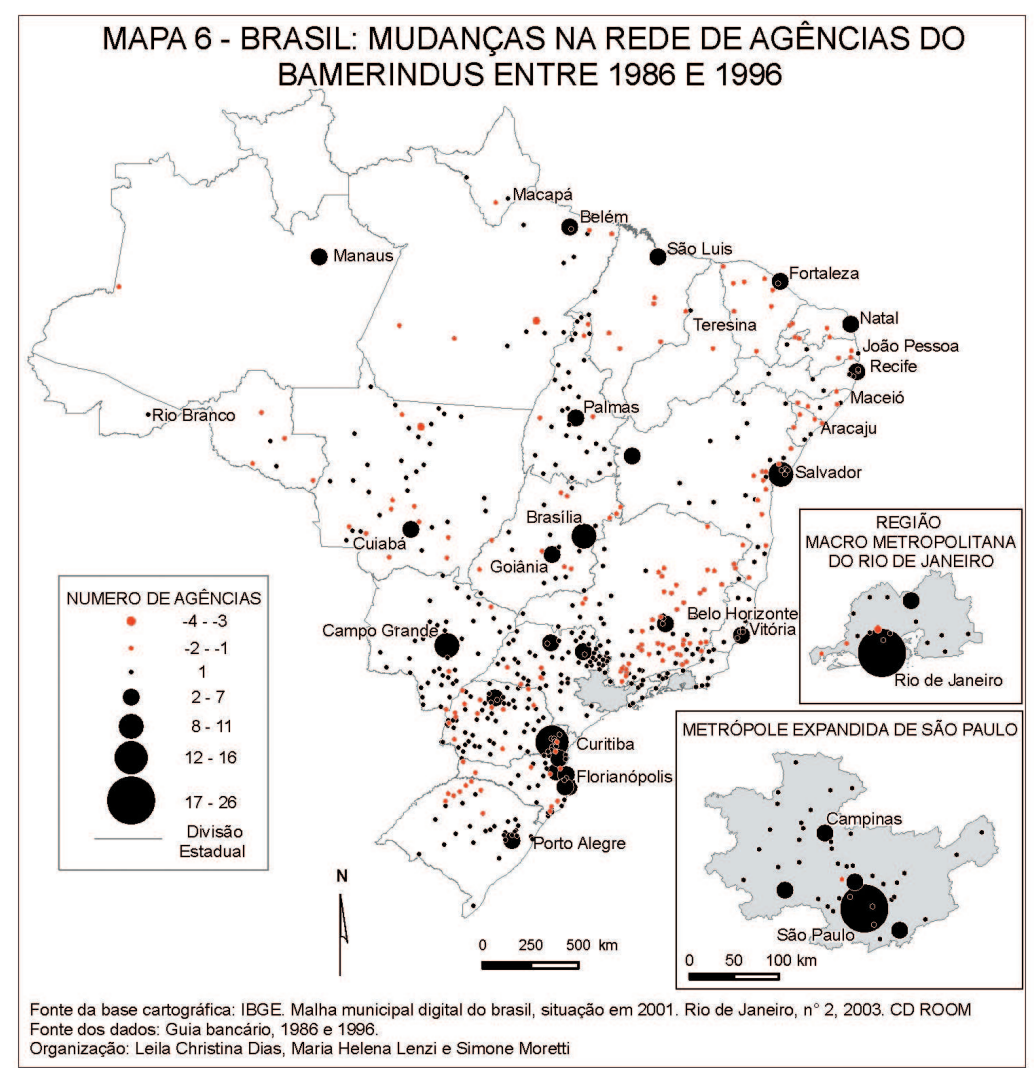

${ }^{5} \mathrm{Na}$ definição de Santos e Silveira (2001), fração do espaço geográfico brasileiro que inclui pontos da economia mais dinâmica com elevado nível de desenvolvimento tecnológico. Região que inicia em Porto Alegre, integra o

Vale do Itajaí e o nordeste catarinense, os estados do Paraná e de São Paulo, a região metropolitana do Rio de Janeiro, a metade sul de Minas Gerais e o Estado de Goiás. 

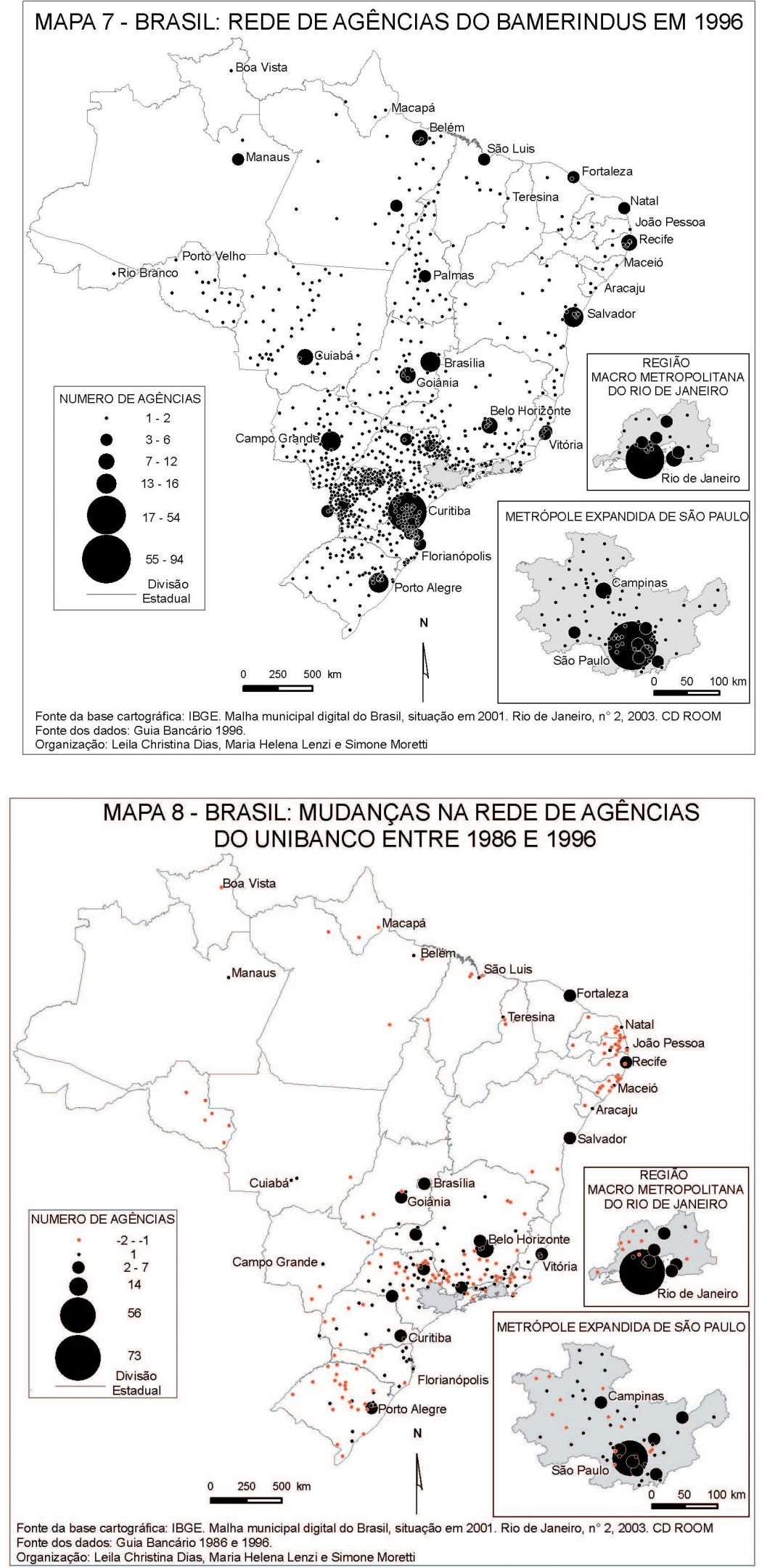


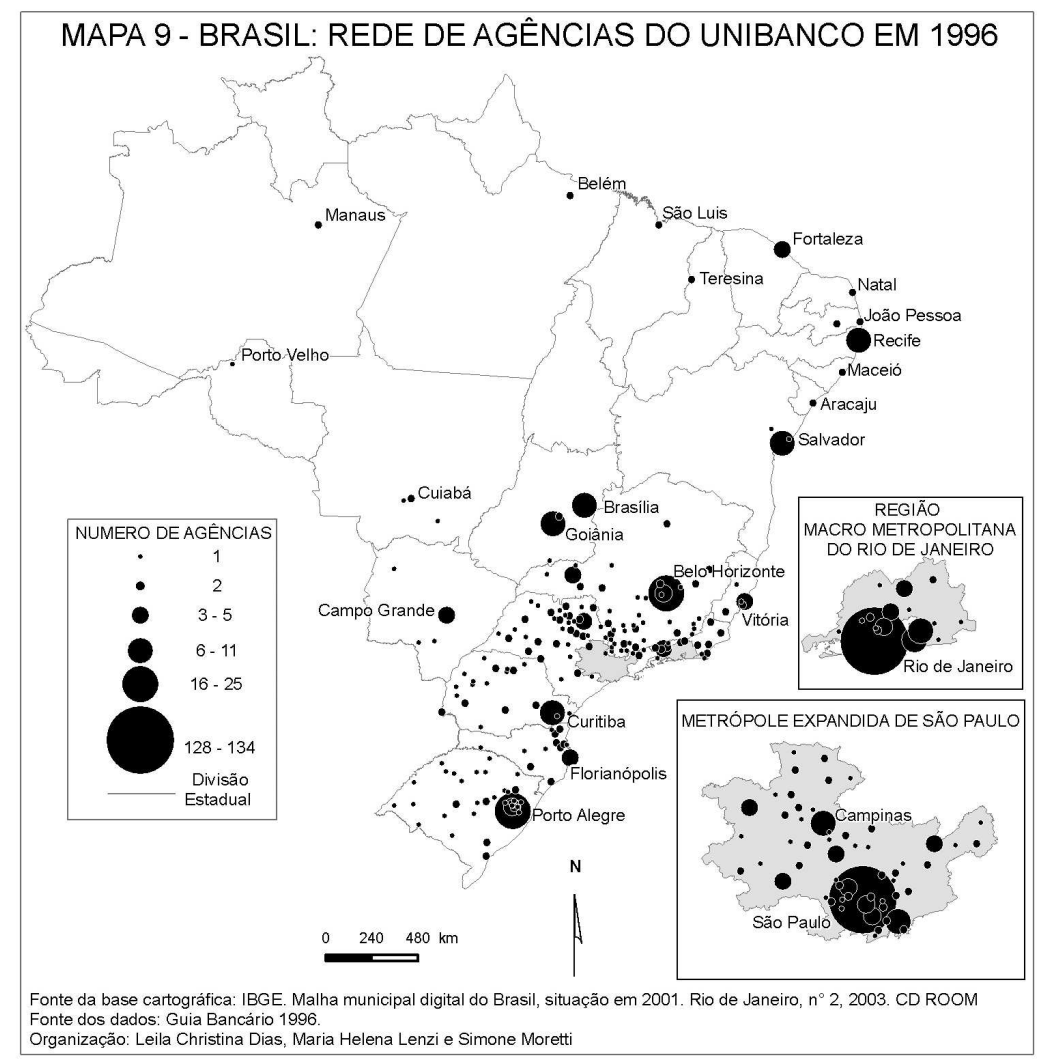

tégias organizacionais, normativas, tecnológicas e corporativas implicará mudanças na geografia das redes bancárias no Brasil?

\section{Processos inovadores e extensão territorial e social das redes bancárias}

No contexto de mundialização financeira dos anos noventa, a visão das instituições monetárias supranacionais e de alguns governos dos países centrais pressupunha que a promoção de estruturas eficazes de supervisão nessas economias estaria diretamente associada à participação de capital estrangeiro nos sistemas financeiros dos países "emergentes". ${ }^{6}$ Bancos europeus foram estimula-

\footnotetext{
${ }^{6}$ Trecho do relatório encaminhado em 1998 pelo Conselho de Análise Econômica da França ao então primeiroministro Lionel Jospin exemplifica tal posição: "No caso específico dos países em desenvolvimento, é necessário destacar que existe uma solução bem simples e eficaz para resolver as insuficiências dos mecanismos de supervisão locais: trata-se da abertura do capital dos bancos a grandes instituições financeiras internacionais que desenvolveram modos de controle interno eficazes“ (Davanne, 1998, p. 22).
}

dos a expandir suas redes para o estrangeiro no contexto de consolidação bancária do sistema financeiro europeu, sob a União Monetária Europeia (Paula, 2002).

Embora a Constituição de 1988 proíba a entrada do capital estrangeiro no sistema financeiro brasileiro, o artigo 52 do ato das disposições constitucionais transitórias abriu espaço para um possível acesso das instituições financeiras estrangeiras, através das autorizações resultantes de acordos internacionais, da aplicação do princípio da reciprocidade e dos casos que o governo julgue de interesse nacional. É nesse contexto que, em agosto de 1995, a Exposição de Motivos no 311 do Ministro da Fazenda, aprovada pelo Presidente da República, expressa a posição do governo brasileiro, que passa a considerar de interesse do país maior participação do capital estrangeiro no sistema financeiro nacional. Em menos de três anos outubro de 1995 a abril de 1998 -, 14 bancos comerciais e múltiplos são autorizados a instalar-se no país, mediante aquisição do controle acionário de bancos nacionais - privados e públicos -, ou 
constituição de sucursais bancárias (Freitas, 1999). Na verdade, a maioria dos bancos europeus que participaram de fusões e aquisições bancárias no Brasil após 1997 já atuava no país através de escritórios de representação, como ilustram, por exemplo, a trajetória do Santander: o banco abre escritório no Brasil em 1982 e adquire os bancos Geral e do Comércio, do Noroeste, o Conglomerado Financeiro Meridional e o Banespa entre 1997 e 2000; e a do HongKong and Shangai Bank Corporation (HSBC), que chega ao Brasil em 1976 através do escritório do banco de negócios londrino Samuel Montagu, torna-se sócio minoritário do Banco Bamerindus entre 1995 e 1997, quando assume seu controle com recursos do PROER, passando a denominar-se HSBC Bamerindus e em 1999 muda o nome para HSBC Bank Brasil (Khalil, 2004). Nos anos 2000, Brasil, México e Argentina concentram na América Latina os ativos financeiros do HSBC, que tem presença bem menos significativa nos outros países da região (vide sítio eletrônico www.hsbc.com). Podemos concluir, parcialmente, que, no bojo do processo de internacionalização bancária, bancos estrangeiros expandem-se geograficamente de maneira desigual e concentrada.

A forma particular da reorganização do sistema bancário no Brasil sugere que a interação entre normas que emanam de uma ordem global e aquelas internas a cada Estado Nação não se dá exatamente da mesma maneira nos diferentes países. Embora México e Brasil, por exemplo, acompanhem a tendência planetária em direção ao crescimento da concentração bancária, a do México é bem superior à do Brasil, que mantém percentuais inferiores aos previstos no início dos anos $2000 .^{7}$ Uma das principais diferenças entre as duas experiências consiste no papel desempenhado pelo

Em 2002, a Austin Asis previu que os dez maiores bancos que operam no Brasil participariam com 90\% dos ativos em 2007, aproximando-se do perfil do México onde as dez maiores instituições concentravam naquele ano 94\% dos ativos (Gazeta Mercantil, 11 abr. 2002, p. B-2). O relatório do Banco Central de 31 de dezembro de 2006 informa que os dez maiores bancos que operam no Brasil participavam com 73,0\% no final de 2006, bem menos que o previsto pela Austin Asis. Disponível em http://www.bcb.gov.br/htms/Deorf/r200612/ quadro23.asp?idpai=REVSFN200612. Acesso em: 29 set. 2008 . capital estrangeiro: enquanto no México, após a grave crise financeira de 1994, as instituições estrangeiras lideraram os processos de reorganização e de concentração bancárias, no Brasil, à mesma época, essas mesmas instituições enfrentaram concorrência de grandes bancos privados nacionais, que integram poderosos grupos financeiros que controlam ou participam de empresas financeiras e não financeiras. Na mesma direção, elas encontraram, no país, um sistema bancário com forte presença estatal, representada pelo Banco do Brasil e pela Caixa Econômica Federal, que ocuparam, até meados de 2008, respectivamente, o primeiro e segundo lugares no ranking do tamanho do setor bancário, por depósitos.

Em tal contexto, o processo de privatização dos bancos públicos estaduais resultou de um conjunto de ações que inclui pressões do Banco Mundial e do FMI sobre governos latino-americanos para reduzir a presença do Estado, papel ativo de bancos privados nacionais e estrangeiros na compra dos bancos estaduais nos leilões da privatização, e ação normativa do Banco Central, que institui, em 1997, o Programa de Incentivo à Redução do Setor Público Estadual na Atividade Bancária (PROES). Os principais argumentos oficiais apontam problemas estruturais nos bancos estaduais em razão da "excessiva concentração de créditos, com elevado grau de inadimplência” e do grande volume de títulos públicos de emissão dos próprios Estados, “o que os torna altamente dependentes de recursos no mercado financeiro, a taxas que, geralmente, se situam bem acima daquelas regularmente praticadas" (Banco Central do Brasil, 1998, p. 11). Entre 1997 e 2005, os bancos dos Estados de Mato Grosso, Alagoas e Amapá foram liquidados, e outros treze bancos estaduais privatizados, em consequência da ação do PROES (Quadro 1).

As ações de saneamento implementadas pelo Banco Central a partir de 1994 - liquidações, intervenções e administrações especiais -, assim como os processos de fusão e incorporação, implicaram importantes movimentos de transferência de controle de instituições, numa lógica que se caracteriza pela concentração bancária: entre 1994 
Quadro 1 - Brasil: bancos estaduais privatizados entre 1997 e 2005

\begin{tabular}{|l|l|l|}
\hline \multicolumn{1}{|c|}{ Bancos estaduais } & \multicolumn{1}{c|}{ Bancos adquirentes } & Datas do leiláo \\
\hline Banco do Estado do Rio de Janeiro S.A. & Itaú & 1997 \\
\hline Banco de Créd. Real de Minas Gerais S.A. & BCN/BRADESCO & 1997 \\
\hline Banco Meridional do Brasil S.A. & Banco Bozano Simonsen & 1997 \\
\hline Banco do Estado de Minas Gerais S.A. & Itaú & 1998 \\
\hline Banco do Estado de Pernambuco S.A. & ABN/AMRO & 1998 \\
\hline Banco do Estado da Bahia S.A. & BRADESCO & 2000 \\
\hline Banco do Estado do Paraná S.A. & Itaú & 2000 \\
\hline Banco do Estado de São Paulo S.A. & Santander & 2001 \\
\hline Banco do Estado da Paraíba S.A. & ABN/AMRO & 2001 \\
\hline Banco do Estado de Goiás S.A. & Itaú & 2002 \\
\hline Banco do Estado do Amazonas S.A. & BRADESCO & 2004 \\
\hline Banco do Estado do Maranhão S.A. & BRADESCO & 2005 \\
\hline Banco do Estado do Ceará S.A. & BRADESCO & \\
\hline
\end{tabular}

Fonte: Organizado por Leila Christina Dias com base nos dados obtidos em: http:/www.bcb.gov.br/lid/gedes/instituiçõesPrivatizadas.pdf. Acesso em 10/11/2004; e http://www1.folha.uol.com.br/folha/dinheiro/ult91u103627.shtml. Acesso em 22/12/2006.

e 2005, o número de bancos comerciais e múltiplos diminui no país, passando de 244 para 160. Esse conjunto de mudanças corresponde a uma segunda fase no processo de reorganização espacial, caracterizada pelo aumento, em termos absolutos e relativos, do número de municípios sem agências e sem postos de atendimento bancários - de 1.681 (29,7\%) em 2001 para 2.271 (40,7\%) em $2007^{8}$ - e da concentração geográfica, como veremos a seguir, com base nas estratégias locacionais dos bancos Bradesco, HSBC e Unibanco.

A evolução espacial do Bradesco entre 1996 e 2005 se caracteriza simultaneamente pela recomposição de sua rede de agências - viabilizada pela compra dos bancos estaduais públicos - e pela extraordinária concentração geográfica de agências, como ilustra a rede no estado do Amazonas. $\mathrm{O}$ fim do ciclo inflacionário e a necessária adaptação ao contexto de relativa estabilidade econômica haviam encolhido a rede de agências entre 1986 e 1996: o banco fechou agências em 22 municípios e permaneceu apenas em 5, dentre os mais populosos do estado - Manaus, Parintins, Tefé, Itacoatiara e Tabatinga. A compra do Banco do Estado do Amazonas foi o instrumento que o Bradesco utilizou para recompor sua rede no Estado, integrando agências em 33 municípios e abrin-

${ }^{8}$ Disponível em: http://www.bcb.gov.br/htms/deorf/ d200812/Quadro\%2006\%20-\%20Munic\%C3\%AD pios \%20com\%20atendimento\%20banc\%C3\%A1rio\%20no\%20Pa\%C3\%ADs.pdf. Acesso em: 09 jan. 2009. do 18 novas agências na capital, Manaus. Processo semelhante aconteceu no estado da Bahia, após a aquisição do banco estadual. O mapa 10 mostra uma rede que cresce na maior parte do estado de São Paulo e nas maiores regiões metropolitanas, destacando-se o expressivo crescimento de agências na fração espacial denominada Metrópole Expandida de São Paulo. ${ }^{9}$ A emergência desse continuum espacial só pode ser compreendida à luz do processo de formação territorial paulista na segunda metade do século vinte. Ao longo das décadas de 1960 e 1970, o aumento do valor da terra na cidade de São Paulo acelerou o processo de deslocamento das indústrias para a periferia. Duas décadas mais tarde, esse processo de deslocalização de atividades no interior da Região Metropolitana (RM) mudou de conteúdo ao serem transferidos para a periferia os centros de processamento de dados de bancos, de indústrias e de empresas públicas (Dias, 1995); a consolidação de um espaço industrial contíguo à RMSP expressa a relação entre expansão da atividade industrial e centralização de serviços produtivos e financeiros na metrópole paulista (Acca, 2004). A rede também se expande no interior da região macrometropolitana do Rio de Janeiro: na metró-

${ }^{9}$ A Metrópole Expandida de São Paulo engloba 136 municípios agrupados em 16 microrregiões: São Paulo, Guarulhos, Osasco, Moji das Cruzes, Franco da Rocha, Itapecerica da Serra, Sorocaba, São José dos Campos, Jundiaí, Campinas, Santos, Bragança Paulista, Limeira, Moji Mirim, Piracicaba e Tatuí (Acca, 2004). 
pole carioca, na sua periferia imediata (Duque de Caxias, Nova Iguaçu), em Niterói, e para a região serrana, onde Petrópolis e Teresópolis crescem demograficamente graças à mudança permanente de uma parcela da população que se desloca da metrópole e demanda serviços bancários.

Em 1997, a aquisição do Banco Bamerindus do Brasil pelo HSBC mudou radicalmente a geografia da rede de agências. À exceção do discreto crescimento em alguns poucos pontos localizados na Metrópole Expandida de São Paulo e em Porto Alegre, o Mapa 11 mostra verdadeiro encolhimento da rede em todo o território nacional. A estratégia do HSBC revela-se, portanto, completamente diferente daquela que norteava as ações do Bamerindus, até então caracterizada pela ampliação da assistência bancária a municípios menos assistidos, em consonância com as antigas diretrizes do Banco Central, nos anos 1980, e com interesses corporativos historicamente localizados no estado do Paraná e nas regiões de expansão da fronteira agrícola. O HSBC amplia a concentração geo- gráfica: entre 1996 e 2005, o número de municípios integrados pela sua rede cai praticamente à metade, passando de 961 para 537, enquanto o número de agências decresce de 1.380 para 904. Outros bancos estrangeiros traçaram os mesmos objetivos após a aquisição de bancos nacionais, como ilustra a tese de Videira sobre o Grupo Santander (2006).

Entre 1996 e 2005, o Unibanco cresce de maneira concentrada, atendendo 271 municípios com 973 agências em 2005, enquanto, em 1996, ele atendia a 273 municípios com 783 agências. A rede se amplia nas Regiões Metropolitanas de São Paulo, Belo Horizonte, Recife, Rio de Janeiro, Curitiba, Salvador e Fortaleza, no Distrito Federal e em quase todas as capitais estaduais. Por outro lado, a rede diminui consideravelmente em alguns pontos dos estados de Minas Gerais, Rio de Janeiro, São Paulo, Paraná, Santa Catarina e Rio Grande do Sul, consequência de ajustes realizados após a aquisição do Banco Bandeirantes, em fins de 2000, pela superposição de agências de ambos naquelas

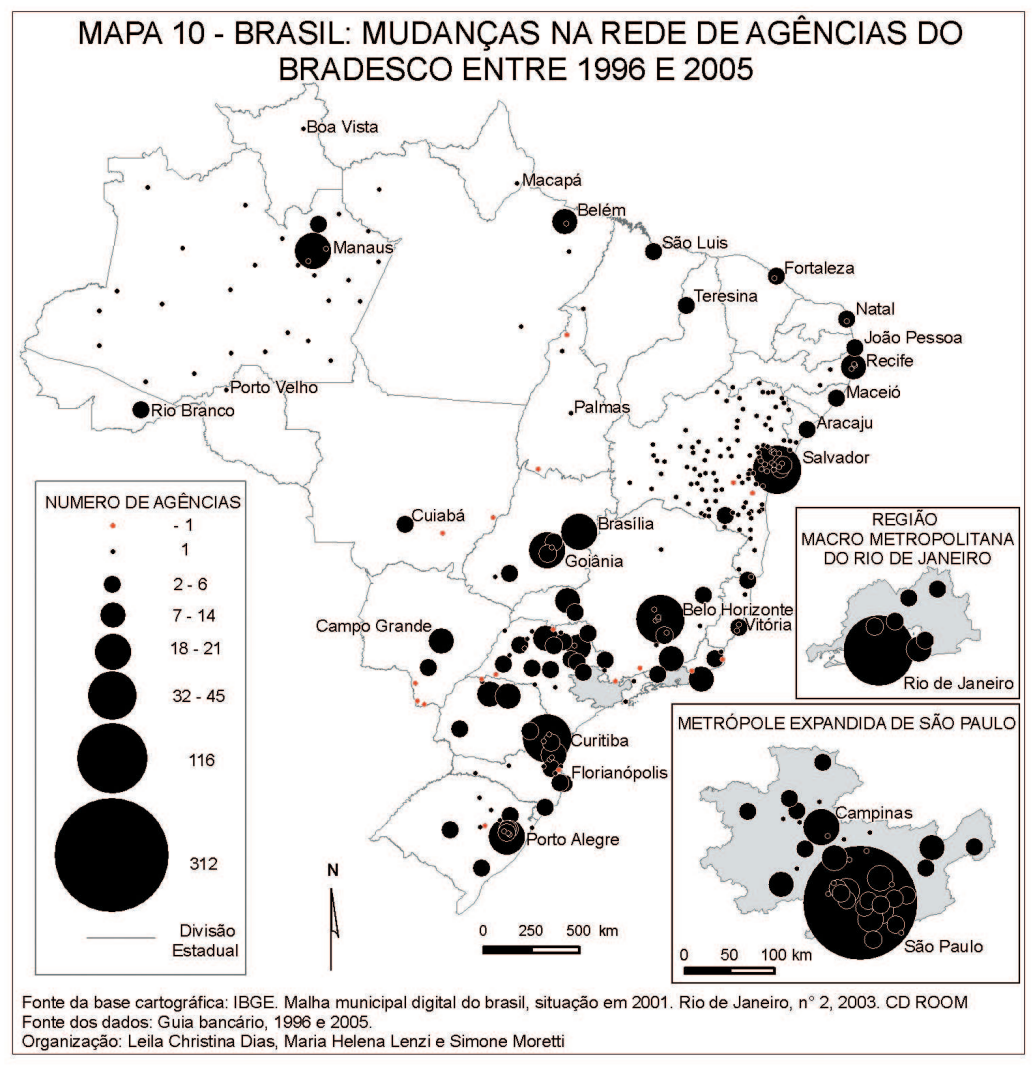




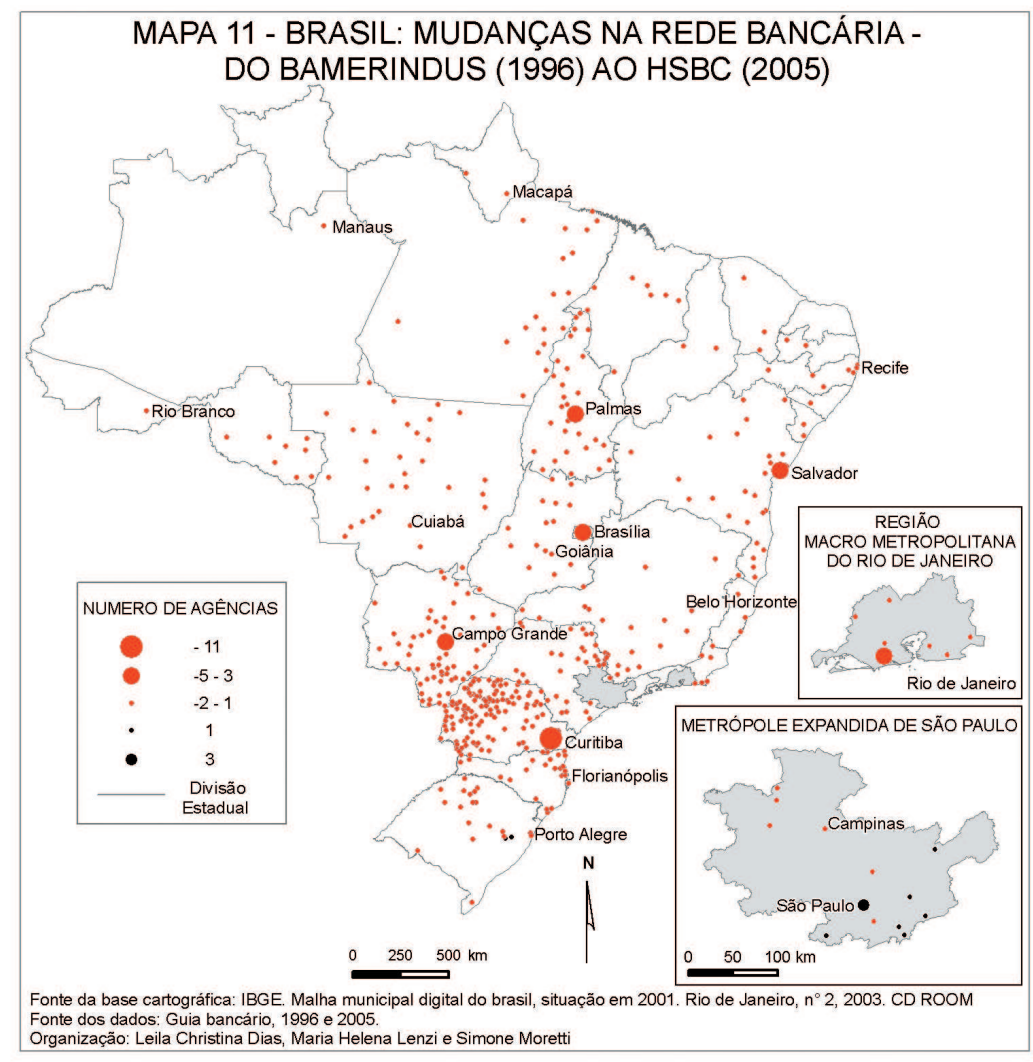

unidades da Federação (Mapa 12).

As redes de agências do Bradesco, HSBC (antigo Bamerindus) e Unibanco tenderam claramente à concentração geográfica, fato que salta aos olhos quando comparamos a geografia das redes em 1986 (Mapas 1, 2 e 3) com a de 2005 (Mapas 13, 14 e 15). Como explicar tamanha mudança na localização de agências bancárias? A distribuição espacial da população não a explica, tampouco a do Produto Interno Bruto (PIB): regiões com o mesmo PIB podem ter números diferentes de agências (Sicsú e Crocco, 2003). Alexandre, Lima e Canuto concluem que “... a atividade bancária não é uma simples sombra da atividade econômica como um todo, tendo, portanto, determinantes locacionais particulares" (2005, p. 26). Esses autores analisam pelo menos duas ordens de fatores que poderiam ter influenciado a atividade bancária brasileira recente: uma de natureza tecnológica e outra de natureza regulatória. A primeira significa que o progresso tecnológico ampliaria o controle dos administradores seniores sobre suas filiadas e reduziria os custos de agência associados à distância, facilitando, portanto, a expansão geográfica (Berger; DeYoung, 2002 apud Alexandre, Lima; Canuto, 2005). A segunda resulta da ação do Banco Central do Brasil, expressa na Resolução nº 2.099 - editada em 1994 - que, reduzindo valores de capital realizado e patrimônio líquido exigidos para instituições que tivessem sede e no mínimo 70\% de suas dependências localizadas fora dos estados do Rio de Janeiro e de São Paulo, busca incentivar a localização de agências fora daqueles estados da Federação. Alexandre, Lima e Canuto (2005) concluem que, no caso brasileiro, esses incentivos não contribuíram para a dispersão geográfica da atividade bancária. Sugerem que, no período recente, a busca de ganhos de escala e de escopo constitui um dos principais elementos explicativos da concentração geográfica ${ }^{10}$ e mostram como as pos-

${ }^{10}$ Alexandre, Lima e Canuto concluíram que "a concentração da atividade bancária em São Paulo é muito mais expressiva quando se consideram as operações bancárias, em vez do número de agências, o que resulta numa relação entre operação bancária e agência muito maior na cidade de São Paulo que nas demais regióes (2005, p. 15). 


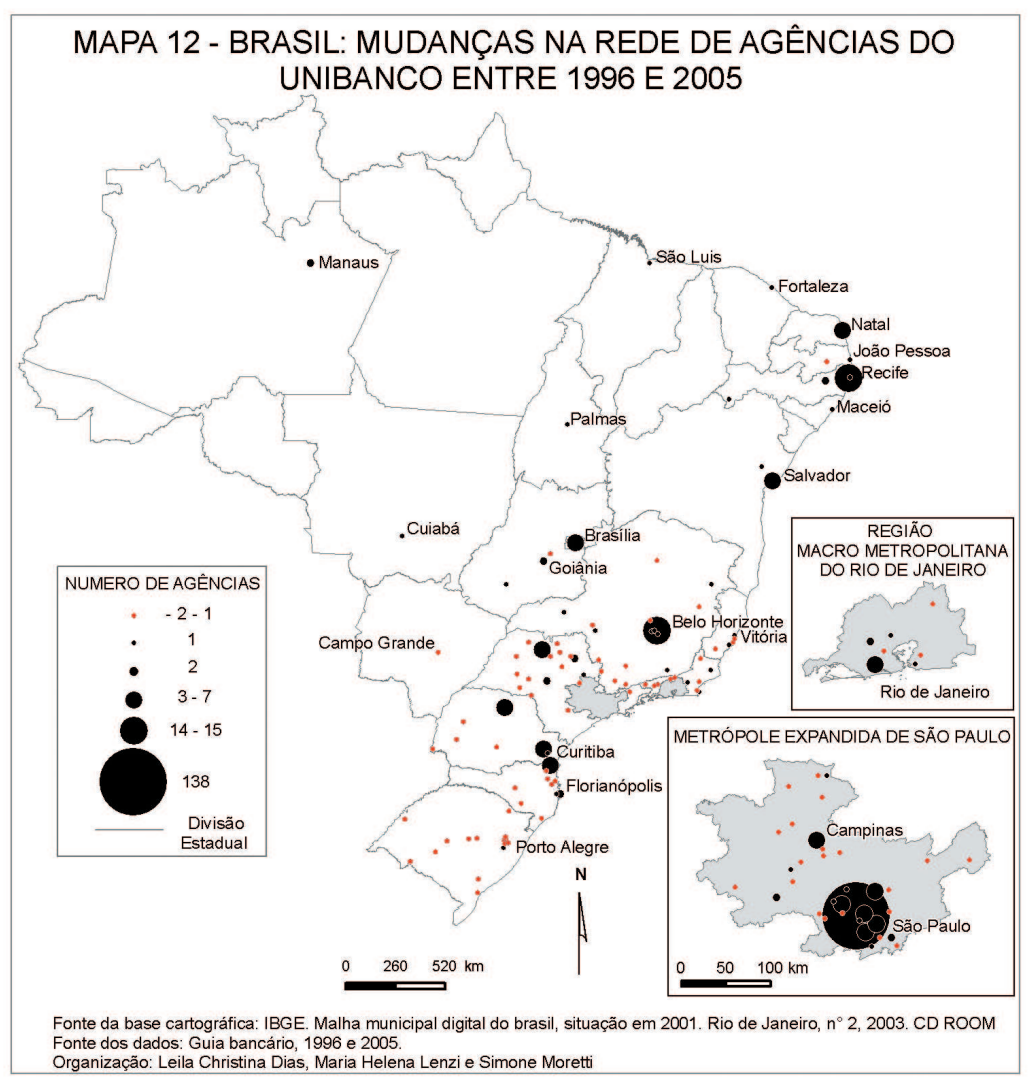

sibilidades desses ganhos incentivam novos processos de fusões e aquisições bancárias (F\&A).

Quando uma F\&A envolve duas (ou mais) instituições que atuam em áreas geográficas distintas, as mudanças administrativas que normalmente se seguem a esse processo geralmente alteram a política de alocação espacial de recursos da nova instituição, resultando em abertura/fechamento de agếncias em algumas localidades, redistribuição regional do crédito e de outros produtos financeiros etc. (2005, p. 27).

Se o conjunto de argumentos aqui apresentados não é falso, parece-nos insuficiente, porque restringe a atividade bancária àquela desenvolvida no âmbito das agências, que, de fato, tenderam à concentração. Contudo, novas tecnologias de informação e comunicação e novo formato organizacional possibilitaram, ao contrário, a presença ativa dos bancos no território, por meio de correspondentes bancários presentes em quase todos os municípios brasileiros. Embora parte da legislação que regulamenta esse serviço não seja propriamente nova-as primeiras regulamentações datam da década de 1970-,é a partir de 1999 que um conjunto de Resoluções do BC organiza esse tipo de atendimento, desenvolvido geralmente por agências lotéricas e outros estabelecimentos comerciais, contratados pelos bancos para a prestação de serviços bancários. A utilização da rede de atendimento da Empresa Brasileira de Correios e Telégrafos pelo Bradesco é talvez o exemplo mais conhecido desse serviço: sob o nome de Banco Postal, são oferecidos serviços de abertura de conta, recebimento de contas e de títulos e tributos, pedido de cartão e talão de cheque, pagamento de salários e benefícios, fornecimento de saldos e extratos, realização de depósitos, saques e transferências e recepção e encaminhamento de pedidos de empréstimo e financiamento. Com o Banco Postal presente em quase cinco mil agências dos Correios, estima-se que o Bradesco tenha incluído, no sistema financeiro, aproximadamente 1,8 milhão de novos clientes em dois anos (Jornal Zero Hora, 06 jun. 2004, p. 19), trazendo para dentro do sistema financeiro e bancário volume considerável de recursos que têm origem em pequenos salários, pensões e aposentadorias do INSS recebidas pe- 
las populações de baixa renda. Estudos acadêmicos e matérias jornalísticas empresariais destacam tanto a emergência de um modelo brasileiro de correspondente bancário, único tanto pelo alcance, escala e qualidade dos serviços prestados quanto pelas novas plataformas tecnológicas que possibilitam a provisão dos serviços (Diniz; Pozzebon; Jayo, 2008), além da disseminação desse conceito para os demais países latino-americanos (Abud Junior, 2008).

Mudanças econômicas, normativas, políticas, tecnológicas e espaciais estiveram assim articuladas num só conjunto interdependente, que resultou numa nova geografia das redes bancárias. À densificação das agências em alguns pontos do território correspondeu a expansão territorial e social sem precedentes das redes bancárias no território brasileiro, que voltaram a crescer graças ao desenvolvimento do correspondente bancário. Paralelamente, ocorreu a centralização da atividade bancária, compreendida como o crescimento do comando das instituições bancárias na metrópole paulista, que, em 2005, acolheu 52\% das sedes dos bancos múltiplos e comerciais que operavam no Brasil, num contexto de redução do número de praças bancárias no país, de 32 para 21 entre 1996 e 2005 (Guias Bancários, 1996, 2005). ${ }^{11}$

\section{CONSIDERAÇÕES FINAIS}

É no encontro de ações empreendidas em diferentes escalas espaciais que o sistema bancário se reorganiza no Brasil a partir dos anos 1980. A ação dos atores hegemônicos internacionais -instituições, governos e banqueiros - leva à aceleração do processo de centralização das instituições financeiras através de fusões e incorporações. Interlocutor de primeira grandeza com os atores internacionais, o Banco Central do Brasil produz normas que, de

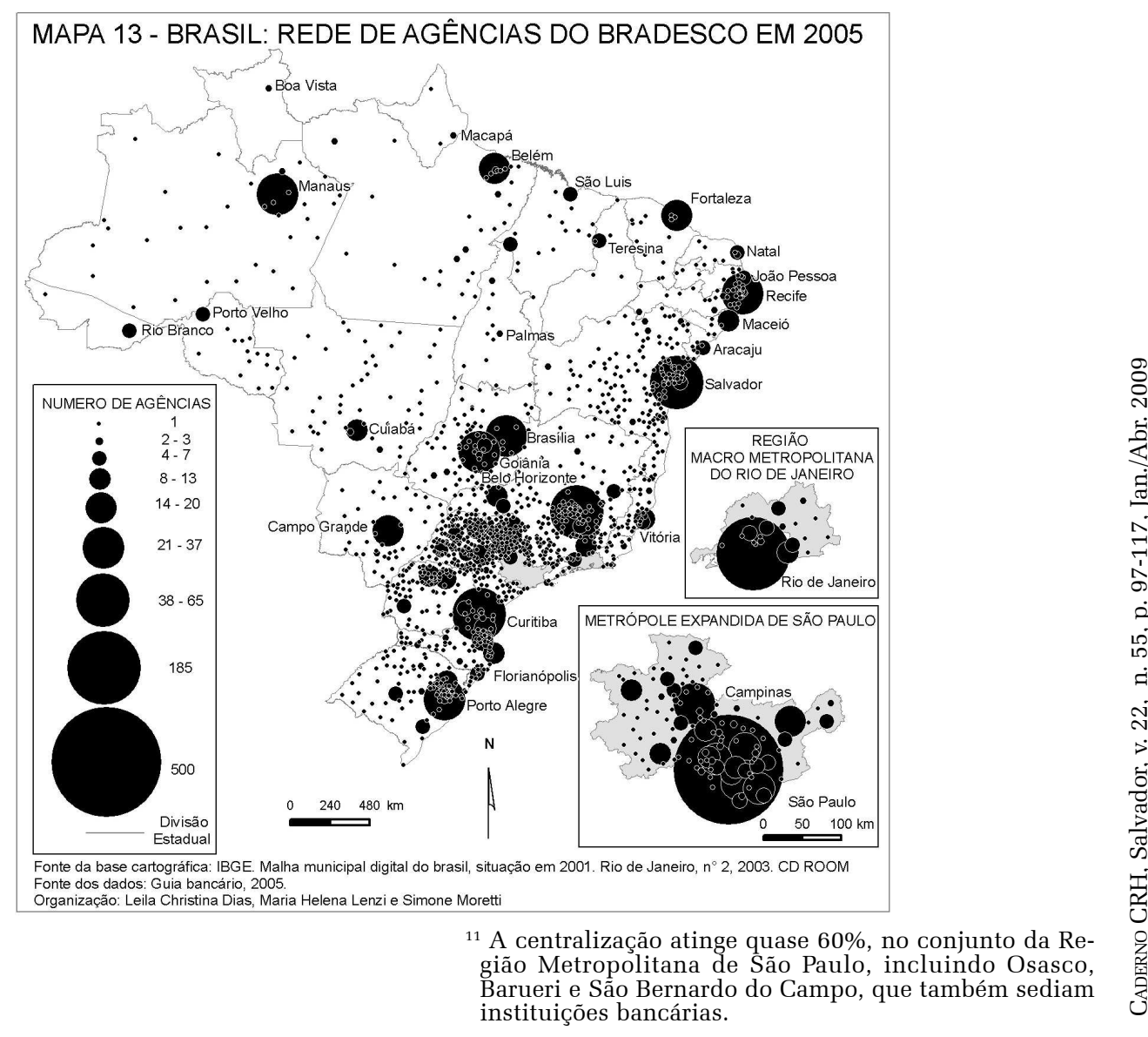




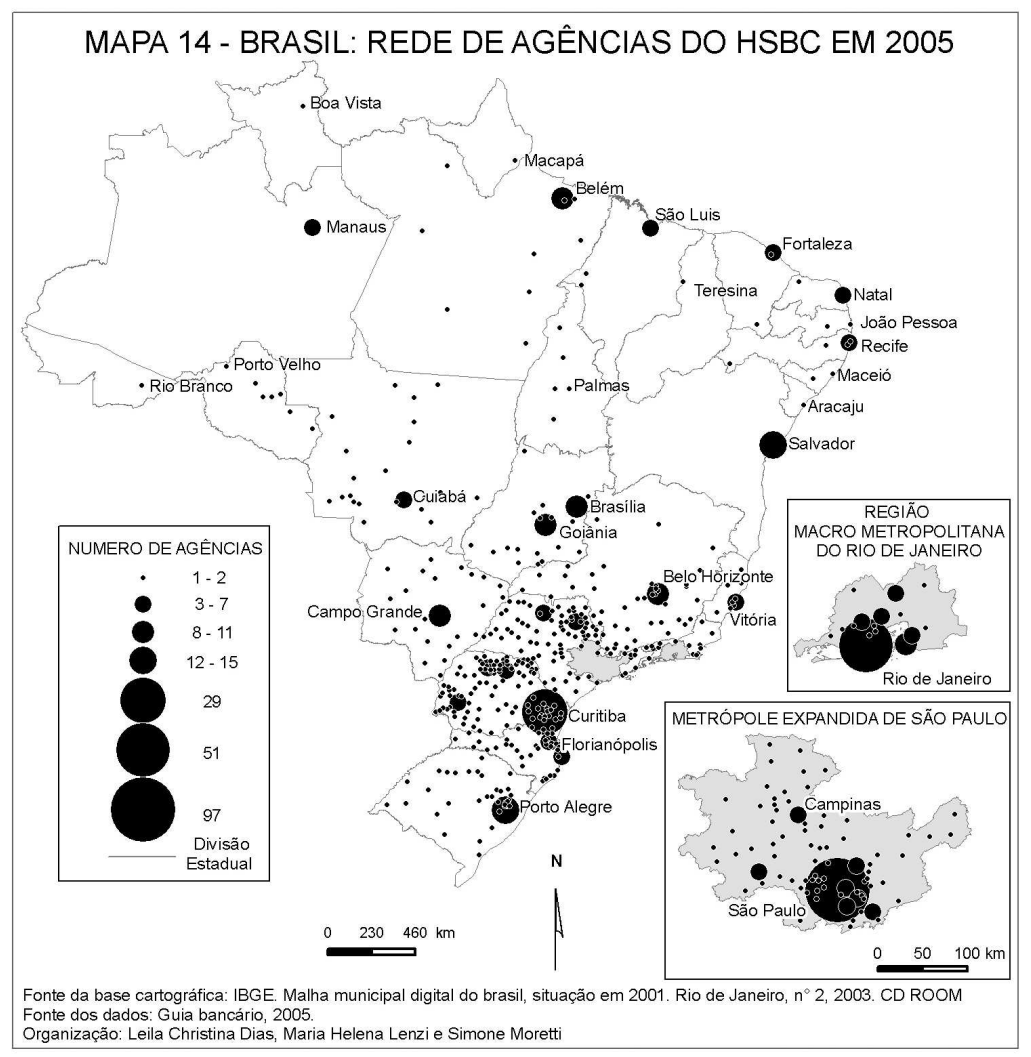

MAPA 15 - BRASIL: REDE DE AGÊNCIAS DO UNIBANCO EM 2005

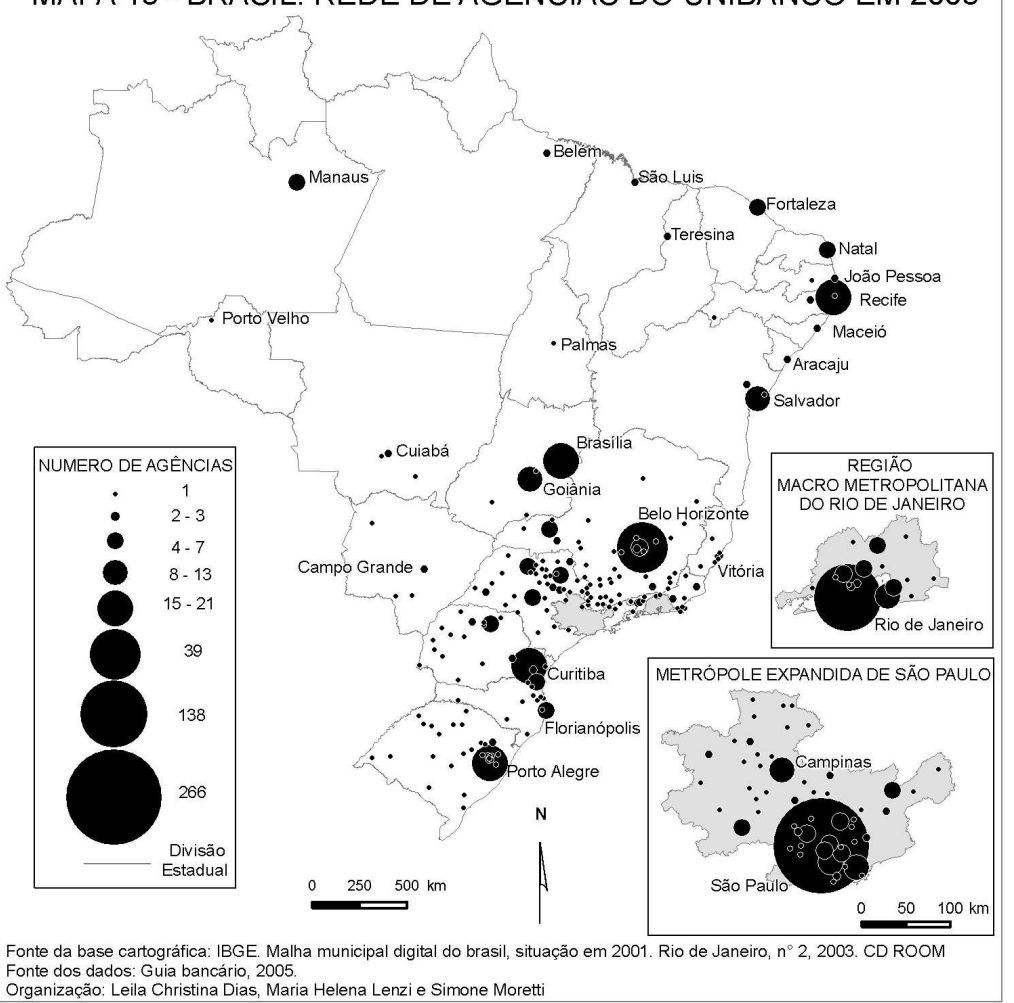


certa forma, adaptam o sistema financeiro à "opinião" internacional. Os banqueiros privados nacionais integram às suas ações os mecanismos que operam na escala internacional, buscando também ampliar a concentração de capital.

Nesse contexto, transforma-se a natureza do trabalho desenvolvido nas agências bancárias, que, além de suas funções tradicionais, passam a comercializar uma gama cada vez mais diversificada de serviços: seguros, previdência, administração de cartão de crédito e gerenciamento de fundos de investimentos. Presentes nos principais centros financeiros mundiais por meio de agências e escritórios próprios e de associações com grupos financeiros internacionais, os bancos prestam assessoria de alocação de ativos, orientação fiscal, tributária e sucessória, viabilizando investimentos no Brasil e no exterior. O núcleo de inovações tecnológicas de base microeletrônica engendra mudanças nas formas assumidas pelo dinheiro e pelas finanças. Dinheiro virtual, cartões magnéticos inteligentes e transferência eletrônica de fundos rematerializam o dinheiro, que se transforma em unidades de informação transmitidas pelas redes de telecomunicações. Limitada inicialmente à escala da agência, a automação das caixas automáticas ultrapassou o limite das agências e se disseminou pelos espaços urbanos, permitindo a difusão dos serviços de autoatendimento. A partir de 1995, com a introdução do home banking, o uso doméstico dos serviços não cessa de crescer: o número de transações bancárias pela Internet passou de 38,7 milhões para 6,2 bilhões entre 1998 e $2006 .^{12}$

Este trabalho procurou mostrar como a reorganização espacial das redes dos grandes bancos privados presentes no país resultou da combinação de processos adaptativos e inovadores: a partir da segunda metade dos anos 1980, condicionantes externos e internos mudaram a trajetória do sistema bancário, o que demandou nova geografia, caracterizada pela retração de agências bancárias no interior de todas as macrorregiões e, simultaneamen-

12 Disponível em: http://www.procomp.com.br/ ci_reportagens_detalhes.asp?id=49. Acesso em: 16 set. 2004; Disponível em: http://www.parana-online.com.br/ te, expansão nas maiores regiões metropolitanas do país; em outras palavras, uma adaptação espacial às novas condições macro e microeconômicas. Contudo essa nova geografia não seria tolerada por muito tempo, levando bancos a inventarem ou reinventarem um objeto híbrido, que combina serviço, tecnologia de comunicação e produto, resultado de uma forma superior de inteligência financeira - como diria Milton Santos (1996) sobre essa capacidade das firmas de inventar novos produtos sob o capitalismo financeiro. Num contexto de aumento da concentração bancária, bancos buscaram economias de escala e de escopo, infraestruturas que dessem suporte às operações financeiras e de capital humano. Ao mesmo tempo inovaram, ampliando seu alcance espacial numa escala sem precedentes através dos correspondentes bancários, reafirmando, assim, o quanto o domínio do espaço constitui fonte de poder para instituições bancárias e financeiras.

(Recebido para publicação em fevereiro de 2009) (Aceito em abril de 2009)

\section{REFERÊNCIAS}

ABUD JUNIOR, J. Cresce demanda por correspondentes bancários. Jornal Diebold, São Paulo, v.17, maio 2008. Disponível em: http://www.diebold.com.br/dweb/ M_JornalDiebold.asp. Acesso em: 09 jan. 2009.

ACCA, R. dos S. A Dinâmica industrial recente da metrópole paulista: das ilusões pós-industriais a novas perspectivas sobre o desenvolvimento metropolitano. 2004. Dissertação (Mestrado em Sociologia) - Universidade de São Paulo, 2004.

ALEXANDRE, M.; LIMA, G. T.; CANUTO, O. Distribuição espacial da atividade bancária no Brasil: dimensões e indicadores. Nova Economia, Belo Horizonte, UFMG, v.15, n.1, p.11-33, jan./abr. 2005.

ALMEIDA, D. B. de C; JAIME JUNIOR, F. G. Bancos e concentração no Brasil: um estudo com dados em painel para os Estados (1995-2004). Disponível em: http:// www.anpec.org.br/encontro2007/artigos/A07A007.pdf. Acesso em: 05 jan. 2009.

ANTUNES, L. R. Considerações preliminares sobre o setor bancário brasileiro na década de 90. In: CONGRESSO LATINO AMERICANO DE SOCIOLOGIA DO TRABALHO, 3, 2000. Buenos Aires: 2000. 35 p.

BANCO CENTRAL DO BRASIL. Evolução do sistema financeiro nacional. Relatório semestral dez. 1998. Disponível em: http://www4.bcb.gov.br/deorf/r199812/texto. htm. Acesso em: 19 set. 2000. 
História do BC. Disponível em: http:// www.bcb.gov.br/?HISTORIABC. Acesso em: 19 dez. 2008.

PROER - Programa de Estímulo à Reestruturação e ao Fortalecimento do Sistema Financeiro Nacional. Disponível em: http://www.bcb.gov.br/htms/ proer. htm. Acesso em: 30 mar. 1998.

CERQUEIRA, H. E. A.; AMORIM, W. A. Evolução e características do emprego no setor bancário. In: CARLEIAL, L. VALLE, R. (Org.). Reestruturacão produtiva e mercado de trabalho no Brasil. São Paulo: HUCITEC, 1997. p. 399-418. CHESNAIS, F. de. A mundialização financeira. São Paulo: Xamã, 1998. 334p.

CONTEL, F. Território e finanças. Técnicas, normas e topologias bancárias. 2007. Tese (Doutorado em Geografia Humana) - Universidade de São Paulo. 2007.

CORAZZA, G. Crise e reestruturação bancária no Brasil. In: ENCONTRO DE ECONOMIA DA REGIÃO SUL ANPEC SUL,3, set. 2000. Porto Alegre, 2000. CD-Rom.

; OLIVEIRA, R. Os bancos nacionais face a internacionalização do Sistema Bancário Brasileiro. In JORNADAS DE ECONOMIA CRITICA ALTERNATIVAS AO CAPITALISMO,10, 2006, Barcelona. Anais... p. 1-24.

CORRÊA, R. L. Concentração bancária e os centros de gestão do território. Revista Brasileira de Geografia, Rio de Janeiro, IBGE, v. 51, n. 2, p. 17-32.abr./jun. 1989.

COSTA, F. N. da. Origem do capital bancário no Brasil: o caso RUBI. Textos para Discussão, Campinas,SP, Instituto de Economia/Unicamp, n.104, mar. 2002.

DAVANNE, O. Instabilité $d u$ système financier international. Conseil d'analyse économique. Paris: La Documentation Française, 1998. 160 p.

DIAS, L. C. Por que os bancos são o melhor negócio no país? Hegemonia financeira e geografia das redes bancárias. In: ALBUQUERQUE, E. S. de (Org.) Que país é esse? São Paulo: Globo, 2006. p. 27-62.

Réseaux d'information et réseau urbain au Brésil. Paris: L'Harmattan, 1995. 172 p.

La géographie du système bancaire au Brésil mutations et tendances. In: PITTE, J. R. SANGUIN, A. L. Géographie et liberté. Paris: L'Harmattan, 1999. p. 359 366 .

DINIZ, E. H.; POZZEBON, M.; JAYO, M. The role of ICT in improving microcredit: the case of correspondent king in Brazil. Cahier du GReSI, Montreal, v.08, n.03, sept. p. 1-23.2008.

FREITAS, M. C. P. de. A ampliação recente da participação estrangeira no sistema bancário brasileiro. Análise Econômica, Faculdade de Ciências Econômicas, UFRGS, v. 17, n. 32, p. 31-49, set. 1999.

GOMES, M. F. A territorialidade do Bradesco: de pequeno banco caipira a maior banco privado de varejo. 2000. 307 f. Dissertação (Mestrado em Geografia Humana) - Faculdade de Filosofia, Letras e Ciências Humanas, Universida- de de São Paulo. 2000.

GUIA bancário brasileiro. 1986, 1996 e 2005. São Paulo: Ed. Guiatec. s.d.

JORNAL GAZETA MERCANTIL. Relatório Bancos. 29 nov. 2002.

KHALIL, Z. Evolução dos padrões de localização das maiores redes bancárias estrangeiras no Brasil 1996-2002. 2004. 67 f. Graduação (Geografia) - Departamento de Geociências, Universidade Federal de Santa Catarina, Florianópolis, 2004.

LENZI, M. H. Configuração territorial das maiores redes bancárias privadas no Brasil entre 1996-2005. 2006. $65 \mathrm{f}$
Graduação (Geografia) - Departamento de Geociências Universidade Federal de Santa Catarina, Florianópolis, 2006 .

MARTIN, R.. The new economic geography of money. In: MARTIN, R. (Org.). Money and the space economy. Chichester: John Wiley \& Sons, 1999. p. 3-27.

MINELLA, Ary C. Banqueiros: organização e poder político no Brasil. Rio de Janeiro: Espaço e Tempo/ANPOCS, 1988. $550 \mathrm{p}$.

PAULA, L. F. de. Expansion strategies of European Banks to Brazil and their impacts on the Brazilian Banking sector. Latin American Business Review, [S.1.], v. 3, n. 4, p. 5991. 2002 .

; MARQUES, M. B. L. Tendências recentes da consolidação bancária no mundo e no Brasil. In: ENCONTRO NACIONAL DE ECONOMIA POLÍTICA, 9, jun., 2004. Uberlândia-MG, Anais... p. 1-25.

PEREIRA, R. C. Automação bancária e informatização do território. 1995. 109f. Dissertação (Mestrado em Planejamento Urbano e Regional) - Programa de Pós Graduação do Instituto de Pesquisa e Planejamento Urbano e Regional, Universidade Federal do Rio de Janeiro, Rio de Janeiro, 1995.

PLIHON, D. Les enjeux de la globalisation financière. In: CORDELLIER, S. (Org.). La mondialisation au-delà de mythes. Paris: La Découverte, 1997. p. 69-79.

SANTOS, M. A natureza do espaço. São Paulo: HUCITEC, 1996. 308p

: SILVEIRA, M. L. O Brasil, território e sociedade no início do século XXI. Rio de Janeiro: Record, 2001. 471p.

SCHERER-WARREN, M. Evolução dos padrões de localização dos cinco maiores bancos privados no Brasil no período 1986-1996. 1999. 59 f. Graduação (Geografia) Departamento de Geociências, Universidade Federal de Santa Catarina, Florianópolis, 1999.

SICSÚ, J.; CROCCO, M. Em busca de uma teoria da localização das agências bancárias: algumas evidências do caso brasileiro. Economia, Niterói-RJ, ANPEC, v. 4, n. 1, p. 85112, jan./jun. 2003.

SILVA, C. A. F. da. Dinâmica espacial do capital bancário - difusão, integração e crise: estudo de caso do Banco Nacional S.A. 1997. 204 f. Tese (Doutorado em Geografia) - Programa de Pós Graduação em Geografia, Universidade Federal do Rio de Janeiro. 1997.

TAVARES, C. V. M. Padrões de localização de bancos privados no Brasil. 1996. 179f. Dissertação (Mestrado em Geografia) - Programa de Pós Graduação em Geografia, Universidade Federal do Rio de Janeiro. 1996.

VIDEIRA, S. L. Dinâmica espacial do sistema bancário no estado de São Paulo. 1999. 153f. Dissertação (Mestrado em Geografia) - Programa de Pós Graduação em Geografia, Universidade Federal de Santa Catarina, Florianópolis. 1999.

A territorialização dos bancos estrangeiros no Brasil: o caso da rede do Santander. 2006. $230 \mathrm{f}$. Tese (Doutorado em Geografia) - Programa de Pós Graduação em Geografia, UNESP, Presidente Prudente. 2006.

VIRILIO, P. Vitesse et politique. Paris: Galilée, 1977. 151p 


\section{SPACE REORGANIZATION OF BANKING CHAINS IN BRAZIL: adaptative and innovative processes}

\section{Leila Christina Dias \\ Maria Helena Lenzi}

The work analyzes the space reorganization of three private banking chains - Bradesco, Bamerindus (currently HSBC) and Unibanco - that appear in the first half of the XX century in São Paulo, Paraná and Minas Gerais. How did those banking chains evolve? How did they interact with other processes that mold their territorial and social extension? This paper examines the external and internal determinants that changed the trajectory of the Brazilian banking system and presents a series of maps that show the location of the branches of those banking chains and their locational changes (1986-1996 and 1996-2005). The conclusion is that this reorganization resulted of the combination of adaptative and inovative processes that demanded a new geography adjusted to the emerging macro and microeconomic conditions. In this process the banks invented or reinvented the banking correspondent, hybrid object that combines service, communication technology and product, making possible a territorial and social expansion unprecedented in the Brazilian territory.

KeYwords: banking chains, space reorganization, banking system, cartography of chains, territory
RÉORGANISATION SPACIALE DES RÉSEAUX BANCAIRES AU BRÉSIL: les processus adaptatifs et innovateurs

\author{
Leila Christina Dias \\ Maria Helena Lenzi
}

Ce travail analyse la réorganisation spatiale de trois réseaux bancaires privés - Bradesco, Bamerindus (actuel HSBC) et Unibanco - qui surgissent dans la première moitié du XXe siècle à Sao Paulo, au Parana et à Minas Gerais. Comment ces réseaux ont-ils évolué? Comment ont-ils interagi avec les autres processus qui définissent leur extension territoriale et sociale? On y analyse également les conditionnements internes et externes qui ont modifié la trajectoire du système bancaire au Brésil et on y présente un ensemble de cartes montrant la localisation des réseaux d'agences de ces banques ainsi que leurs changements de lieu (1986-1996 et 19962005). On en arrive à la conclusion que la réorganisation est le résultat d'une combinaison de processus d'adaptation et d'innovation issus d'une nouvelle géographie ajustée aux conditions macro et micro économiques émergentes. Dans ce processus, les banques ont inventé ou réinventé le correspondant bancaire, objet hybride qui associe le service, la technologie de communication et le produit en viabilisant une expansion territoriale et sociale sans précédent sur le territoire brésilien.

MoTS-CLÉs: réseau bancaire, réorganisation spatiale, système bancaire, cartographie des réseaux, territoire.

Leila Christina Duarte Dias - Doutora em Geografia pela Universidade de Paris IV, Professora do Departamento de Geociências, Universidade Federal de Santa Catarina, coordena o Núcleo de Pesquisa Redes e Organização Territorial, desenvolvendo pesquisas na área da Geografia das Redes Financeiras. É autora do livro Réseaux d'information et réseau urbain au Brésil (Paris, L'Harmattan, 1995), co-organizadora das coletâneas Villes et régions au Brésil (Paris, L’Harmattan, 2000) e Redes, Sociedades e Territórios (Santa Cruz do Sul, UNISC, 2007), e autora de inúmeros artigos publicados no Brasil e no exterior.

Maria Helena Lenzi - Bacharelado em Geografia - Universidade Federal de Santa Catarina, 2006. Mestranda em Geografia - Programa de Pós Graduação em Geografia/UFSC. Integra o Grupo de Pesquisa Redes e Organização Territorial, desenvolvendo pesquisas na área de Geografia Urbana. Suas mais recentes publicações são: LENZI, Maria Helena; GONÇALVES, Tiago. Florianópolis e as imagens da cidade: a expansão dos equipamentos turísticos. In: $10^{\circ}$ Encuentro Internacional Humboldt, 2008, Rosário. DIAS, Leila; LENZI, Maria Helena; GONÇALVES, Tiago. O processo de publicização de Florianópolis: imagem, turismo e finanças como elementos para uma análise geográfica. In: $12^{\circ}$ do Encuentro de Geógrafos de América Latina, 2009, Montevideo. 
